cases thus operated on recover, proviled there be neither tubercle nor amyloid disease present. My own experience is limited to three patients, all of whom made a good recovery. In one case dangerous collapse followed the operation, and the patient was only rallied by the most energetic measures. Resection of the ribs is frequently an absolute necessity from the manner in which the ribs get wedged down one upon the other. I have seen one case where the space between the ribs at the inferior angle of the scapula was barely sufficient to admit the edge of a knife. I am disposed to think that in all cases a very free incision is desirable, and that a thoroughly free exit for the pus should be secured at all hazards. I see no advantage in the plan of making two openings, which is a favourite method at some hospitals. As regards (e) irrigation, the present feeling is against its employment. Accidents have been reported from this procedure, and unless in cases of very foul pus, no advantage seems to accrue from it.

\section{THE PERCENTAGE OF FIBRIN IN THE BLOOD OF LEPERS.}

BY BEAVEN RAKE, M.D.LOND,

MEDICAL SUPERINTENDENT OF THE TRINIDAD LEPER ASYLUM.

THIs inquiry was made in Trinidad, and was suggested by a case which occurred there. On opening the body of an anæsthetic leper a thoracic aneurysm was found which had undergone spontaneous cure. ${ }^{\mathrm{T}}$ The blood in leprosy was examined many years ago. Danielssen and Boeck ${ }^{2}$ made fourteen analyses-eight in tuberculated and six in anæsthetic lepers, - and found the highest percentage of fibrin to be 0.6 per cent., and the lowest 0.22 per cent. Hillairet ${ }^{3}$ also made three analyses of blood in cases of taberculated leprosy, and found that the percentage of fibrin ranged from 0.31 to 0.61 .

We cannot now accept the theory of Danielssen and Boeck, that the excess of fibrin and albumen in the blood is the primary cause of the other leprous changes. An examination of leper blood is, however, not without interest; for though there is reason to believe that leprosy is due to a bacillus, the changes which are produced in the blood, either directly or indirectly, are of no little importance. Thus the rapidity with which leprous tissues neal after operation is well known to those in charge of asylums, and has already been referred to by the writer. ${ }^{4}$ Also the spontaneous formation of firm laminated clot in an aneurysm of the arch of the aorta is unfortunately by no means common. Another noteworthy fact was the rapid coagulation of blood in an anæsthetic leper, in whom the great tos was being explored for dead bone in the Trinidad Asylum. The blood clotted so quickly that it fell in round beads into the basin of water above which the operation was being performed. These beads remained undissolved in the water. The percentage of fibrin in this patient was afterwards found to be $1 \cdot 25$. It seemed, therefore, that an attempt to estimate the fibrin in leprosy extended over a number of subjects might not be without value. For this purpose fifty lepers were chosen from those in the asylum. An endeavour was made to obtain a nearly equal number of persons suffering from each of the three forms of leprosy, but otherwise they were chosen without selection, the blood being chiefly collected from ope"a. tion cases. In these there is the fallacy that in cases of sinus or ulcer there may be a certain amount of local inflammation causing effusion of fibrin factors in the tissues. As far as possible this source of error was avoided by collecting the blood in such cases after the first gush had taken place. In each case the blood was collected in a test tube and immediately whipped with a rough piece of wood to collect the fibrin. The teso tube, wood, and blood were then weighed together. The clot was afterwards detached from the piece of wood, lefo to soak for some hours to detach blood-corpuscles, dried on blotting paper, and weighed. 1 Path. Soc. Trans, , vol. xxxviii., p. 120.

3 Ann. de Dermat. et Syphilog. (Paris), tome v., No. 3.

4 The LaNCET, Sept. 25th, 1886, p. 581 .
The test tube and wood were also washed, dried, and weighed, their weights being deducted from the original total weight. The remainder gave the weight of the blood, and that of the dried fibrin being also known, the percentage was easily calculated.

The accompanying table shows that the range of percentages obtained by this method was very great, the lowest percentage being 0.12 , the highest 1.87 . The blood in this

Table showing Percentages of Fibrin in Fifty Observations.

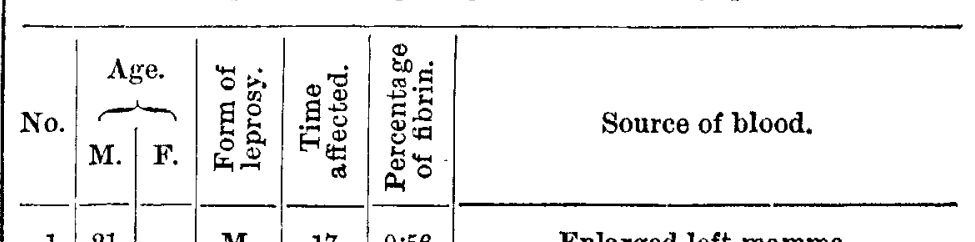

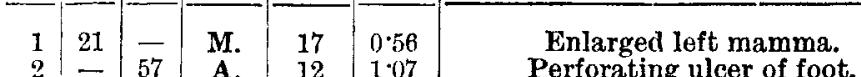

\begin{tabular}{r|r|r|r|r|r|r}
3 & $\overline{3}$ & 57 & A. & 12 & 1.07 & Terforating ulcer of foot. \\
Large tubercle of hand.
\end{tabular}

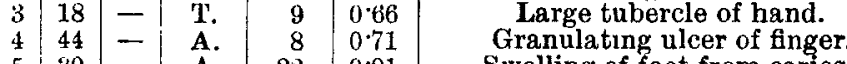

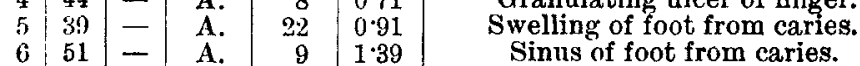

\begin{tabular}{c|c|c|c|c|c}
7 & - & 25 & T. & 4 & 1.33
\end{tabular}$\left\{\begin{array}{r}\text { Infiltration of arm after acute } \\
\text { leprosis. }\end{array}\right.$

$7-25$ T. 4 leprosis.

8 - 66 A. 2 $1.02 \quad$ Stump of amputated toe.

10 - 11 T. 10 .

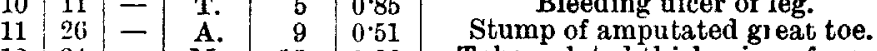

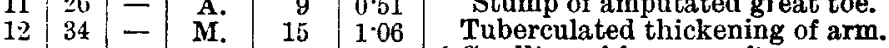

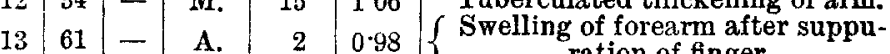

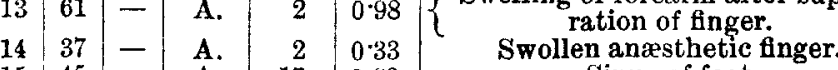

\begin{tabular}{l|lll|l|l|l}
15 & 45 & - & A. & 17 & 0.89 & Sinus of foot.
\end{tabular}

\begin{tabular}{llll|l|l|l}
16 & 41 & - & A. & 12 & 0.73 & Stye of npper lid.
\end{tabular}

Sinus of great toe.

Tubercles of hand.

Tuberculated thickening of finger. Sinus of foot.

Tubercle of face and tissues at elbow.

Sinus of great toe.

Ulcerating tubercles of foot. Sinus of finger.

Tissues in front of forearm. Sinus of foot. Sinus of finger. Ulcer of sole. Sinus of foot.

Swelling of finger from necrosis.

Swelling of finger from necrosis Sinus of foot. Sinus of foot. Swelling of foot. Swelling of finger.

Exuberant granulation of foot. Tubercles of face. Sinus of great toe.

Tuberculated thickening of hand. Tubercles of nose.

Tuberculated thickening of hand. Sinus of toe

Swelling of ball of toe.

Tissues in front of forearm.

Tissues in front of forearm.

Infiltrated tissue of leg and foot. Ulcer of toe. Swelling of leg.

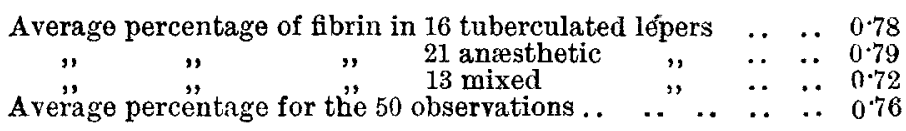

case, however, was collected from an incision at the side of a large hamorrhagic ulcer of the leg, so that there was a possibility of the existence of the fallacy above noted. Taking, however, the average in the three forms of leprosy, there was seen to be a remarkable constancy in the percentage of fibrin. Thus in sixteen tuberculated cases the mean percentage was 0.78 , in twenty-one aræesthetic cases it was 0.79 , and in thirteen mixed cases it was 0.72 . The mean percentage in the fifty lepers amounted to $0 \cdot 76$. In Danielssen and Boeck's fourteen observations the average percentage of fibrin was $0 \cdot 36$, while in Hillairet's three observations it was 0.65. Allowing, therefore, for the errors of experiment already mentioned, the mean percentage calculated on an increased number of observations and subjects agreed approximately with the results previously obtained from more limited records. The table contains details of the observations. Io is noteworthy that in only two of the fifty cases was the percentage of fibrin below 0.2 -the quantity said to be present in healthy human blood. 